\title{
PEDAGOGICAL CONTENT KNOWLEDGE (PCK) CALON GURU SD MELALUI MATA KULIAH PENGEMBANGAN DAN PRAKTIK PEMBELAJARAN BAHASA DAN SASTRA SD
}

\author{
M. Fakhrur Saifudin 1 , Hanum Hanifa Sukma² \\ 1,2PGSD FKIP Universitas Ahmad Dahlan \\ Email: fakhrur.saifudin@pgsd.uad.ac.id
}

\begin{abstract}
Abstrak
Penelitian ini bertujuan untuk (1) mendeskripsikan konsep Pedagogical Content Knowledge (PCK) pada mata kuliah P3 Bahasa dan Sastra SD bagi calon guru SD; (2) Mendeskripsikan kajian aspek Pedagogical Content Knowledge (PCK) dalam mata kuliah P3 Bahasa dan Sastra SD. Metode penelitian ini menggunakan deskriptif kualitatif. Subjek penelitian ini yaitu mahasiswa calon guru SD penempuh mata kuliah P3 Bahasa dan Sastra Indonesia. Sumber data penelitian berasal dari aktivitas dan tindakan selama proses pembelajaran dimulai dengan perencanaan, implementasi, dan penilaian dengan mengintegrasikan kosep PCK. Teknik pengumpulan data menggunakan observasi, wawancara, dan angket sebagai dasar untuk menentukan sejauh mana kajian PCK dalam pembelajaran pada mata kuliah P3 Bahasa dan Sastra Indonesia.Teknik keabsahan data menggunakan tringaulasi sumber data. Teknik analisis data menggunakan model interaktif dimulai dari sajian data, reduksi data, verifikasi data, dan penarikan simpulan. Hasil penetian ini mendeskripsikan tentang muatan PCK dalam makul P3 bahasa dan Sastra SD. Wujud muatan tersebut diintegrasikan dalam beberapa proyek yang telah dilakukan mahasiswa antara lain: penyusunan RPP, modul, media, dan penilaian. Berdasarkan temuan data bahwa mahasiswa telah mengintegrasikan muatan (content) berupa kemampuan berbahasa dan bersastra yang dituangkan dalam bentuk kerja mandiri siswa. Selanjutnya, muatan pedagogi diintegrasikan dalam teks yang dibangun dalam sebuah jalinan tema-tema. Kajian aspek PCK yang ditemukan bahwa mahasiswa telah memenuhi muatan content dan pedagogi dalam penyusunan perangkat bahan ajar yang telah dibuat. Sehingga mahasiswa mampu mengembangkan bahan ajar tematik SD sesuai dengan kompetensi inti dan kompetensi dasar yang telah ditentukan. Dalam praktiknya, mahasiswa mengaitkan materi-materi yang lain sebagai wujud pembelajaran tematik dalam kerangka PCK
\end{abstract}

Kata kunci: Pedagogical Content Knowledge (PCK), pembelajaran, materi SD

\section{Pendahuluan}

Pedagogical Content Knowledge (PCK) merupakan perpaduan kemampuan khusus dari pengetahuan konten dan pedagogik yang terbentuk seiring dengan waktu dan bertambahnya pengalaman mengajar. PCK salah satu kompetensi yang diperlukan mahasiswa calon guru yaitu mahasiswa PGSD. Menurut Sulastri (2016) PCK merupakan kombinasi dari dua unsur yaitu
Content Knowledge (CK) dan Pedagogical Knowledge (PK). Kedua unsur tersebut memiliki peran yang sangat penting dalam menciptakan mahasiswa calon guru sebagai tenaga professional kependidikan ketika terlibat dalam proses belajar mengajar. Content Knowledge yang baik adalah pemahaman dan penguasaan materi dengan permasalahan kehidupan nyata yang sangat mendukung dalam membentuk dan memepengaruhi 
pengetahuan serta proses berpikir siswa. hal tersebut harus seimbang dengan Pedagogical Knowledge atau cara mengajar dan mengelola kelas, agar terciptanya pembelajaran yang efektif. PCK menggambarkan kemampuan guru mengintegrasikan antara Content Knowledge dengan Pedagogical Knowledge. Akan tetapi, menurut Purwianingsih (2011), kesulitan yang sering dialami oleh calon guru adalah mengintegrasikan Content Knowledge dengan Pedagogical Knowledge.Beberapa studi menunjukan bahwa calon guru kurang dalam pemahaman konseptual dan konten yang akan diajarkan.hal ini dikarenakan banyaknya calon guru yang lebih menekankan pemahamannya pada Content Knowledge.

Mahasiswa calon guru masih terfokus pada pemahaman Content Knowledge saja, menurut Sulastri (2016) Content Knowledge yang baik pada calon guru dapat terjadi apabila Pedagogical Knowledge calon guru dalam mengorganisasikan pembelajaran juga baik. Hanya saja saat ini fokus perhatian calon guru lebih pada Content Knowledge yaitu pemahaman materi yang diajarkan. Kurangnya pemahaman mengenai cara mengajar serta pengetahuan tentang manajemen kelas, tugas, perencanaan pembelajaran dan pembelajaran siswa atau yang disebut Pedagogical Knowledge mengakibatkan proses pembelajaran yang kurang bermakna bagi siswa. sebagai calon guru lebih baik memahami kedua unsur yang terdapat pada PCK, sehingga akan terciptanya guru atau tenaga kependidikan professional yang dapat mengembangakan proses belajar dan mengajar di kelas dengan baik.

Guru yang profesional adalah guru yang tidak hanya mempunyai pengetahuan tentang konten materi (Content Knowledge) saja, tetapi juga pengetahuan pedagogi (Pedagogical Knowledge) (Yulianti, 2017). Pentingnya pemahaman Content Knowledge dan Pendagogical Knowledge pada mahasiswa calon guru PGSD karena untuk memudahkan guru/calon guru membelajarkan siswa secara maksimal.Menurut Maryono
(2016) Pemahaman Pengetahuan pedadogi bertujuan untuk membantu guru menyiapkan rencana pembelajaran, lembar aktivitas, dan media pembelajaran secara baik. Selain itu, peningkatan kinerja professional dan aktualisasi dirimenunjukkan upaya berkelanjutan dari guru untuk meningkatkan profesionalisme diri.

PCK sangat terkait dengan tuntutan terhadap kompetensi guru di Indonesia menurut UU Nomor 14 Tahun 2005 Tentang Guru dan Dosen.Hal ini meliputi empat kompetensi salah satunya adalah kompetensi pedagogik, kompetensi pedagogik adalah pemahaman terhadap siswa, perancangan dan pelaksanaan pembelajaran, evaluasi hasil belajar, serta pengembangan siswa untuk mengaktualisasikan berbagai potensi yang dimilikinya. Kompetensi pedagogik merupakan syarat utama dalam menyelenggarakan pembelajaran yang efektif bagi para siswa untuk mencapai tujuan pendidikan (Maryani,2016). Kompetensi pedagogik calon guru harus diperkuat atau diperdalam agar terbentuknya guru/ calon guru SD yang professional.

Berdasarkan hasil observasi awal diidentifikasi bahwa mahasiswa penempuh mata kuliah P3 Bahasa dan Sastra Indonesia belum secara optimal dapat mengintegrasikan kemampuan pedagogik dalam pembelajaran hal ini terbukti bahwa mahasiswa masih terfokus pada aspek Content Knowledge. Selanjutnya, dalam penyusunan tugastugas mahasiswa banyak terdapat beberapa miskonsepsi atau kesalahan konsep tentang pembelajaran Bahasa dan Sastra Indonesia di Sekolah Dasar.

Hasil evaluasi pembelajaran mata kuliah P3 Bahasa dan Sastra Indonesia menunjukan rendahnya kemampuan menggunakan strategi, teknik, dan metode pembelajaran Bahasa dan Sastra dalam praktik pembelajaran. Selanjutnya, mahasiswa masih perlu mengintegrasikan aspek PCK dalam praktik pembelajaran di kelas. 
Pengembangan media pembelajaran Bahasa dan Sastra Indonesia hanya sebatas menyusun secara konseptual, belum pada tataran mengintegrasikan PCK dalam penyusunan media pembelajaran Bahasa dan SastraIndonesia.Mahasiswacalongurusekolah dasar dalam mata kuliah P3 Bahasa dan Sastra Indonesia hanya diarahkan pada pembuatan media, mahasiswa belum diajarkan bagaimana cara menyampaikan pesan yang terkandung dalam media yang disusun. Sehingga, mahasiwa calon guru lebih terfokus pada pembuatan media tanpa mempertimbangkan bagaimana cara menyampaikan materi dan menghubungkannya pada media yang telah dibuat sehingga aspek Pedagagogical Knowledge belum terlihat pada mahasiwa di mata kuliah P3 Bahasa dan Sastra Indonesia.

Pemahaman Pedagogical Content Knowledge (PCK) pada mahasiswa calon guru SD belum maksimal.Mata kuliah Pengembangan dan Praktik Pembelajaran Sastra SD diharapkan dapat membantu mahasiswa memahami dan menggali PCK yang ada pada dirinya.Mata kuliah P3 Bahasa dan Sastra Indonesia SD membahas mengenai beberapa materi Bahasa dan Sastra Indonesia di SD, selain itu pada mata kuliah ini juga memberikan kesempatan mahasiswa calon guru SD untuk melakukan praktik mengajar. Pada praktik mengajar itulah, dapat diketahui apakah mahasiswa calon guru SD sudah memahami PCKataubelum.MenurutAgustiani (2015) Pengetahuan konten mahasiswa calon guru dapat dilihat ketercapaiannya melalui hasil belajar di akhir perkuliahan.Sedangkan pengetahuan pedagogik konten mahasiswa calon guru dapat dilihat perkembangannya melalui hasil belajar di akhir perkuliahan, kegiatan pelaksanaan Praktik Mengajar, dan penyelesaian tugas akhir mahasiswa.

Mata kuliah P3 Bahasa dan Sastra Indonesia SD merupakan pengembangan dari mata kuliah sebelumnya yaitu Materi Pembelajaran Bahasa dan Sastra Indonesia di SD. Pada mata kuliah Materi Pembelajaran Bahasa dan Sastra Indonesia di SD, mahasiswa calon guru SD mempelajari konsep pembelajaran bahasa dan sastra. Setelah materi dan konsep pembelajaran bahasa dan sastra Indonesia di pelajari, maka dikembangkanlah praktik pembelajaran bahasa Indonesia dalam mata kuliah P3 Bahasa dan Sastra Indonesia $\mathrm{SD}$, yang dikembangkan dapat berupa bahan ajar, media pembelajaran dan praktik mengajar yang dapat menggali apakah mahasiswa calon guru SD sudah memiliki Pedagogical Content Knowledge (PCK) yang baik atau belum.

Adapun tujuan penelitian ini adalah (1) mendeskripsikan implementasi konsep Pedagogical conten knowledge (PCK), (2) mendeskripsikan kajian aspek pedagogical content Knowledge (PCK) dalam mata kuliah P3 Bahasa dan Sastra SD. Melalui penelitian ini diharapakan dapat mengetahui kedalaman integrasi PCK dalam setiap proyek tugas mata kuliah. Sehingga nantinya mahasiswa calon guru mampu menyeimbangkan antara muatan konten dan muatan pedagogic dalam mengebangkan bahan ajar.

\section{Metode Penelitian}

Jenis penelitian ini adalah penelitian kualitatif-deskriptif, yaitu mendeskripsikan aspek Pedagogic Content Knowledge melalui integrasi mata kuliah Pengembangan dan Praktik Pembelajaran Bahasa dan Sastra Indonesia (P3Bahasa Indoensia) pada mahasiswaPGSDFKIPUAD.Dalampenelitian ini, peneliti sebagai instrumen berperan aktif dalam menggali informasitentang aspek-aspek PCK dalam proses perkuliahan P3 Bahasa dan Sastra Indonesia. Penelitian ini dimaksudkan untuk mengkaji dan menemukan fenomena apa yang dialami oleh subjek penelitian yaitu perilaku, persepsi, motivasi, tindakan, dan lain-lain (Moleong, 2011:6).

Subjek penelitian ini yaitu mahasiswa penempuh mata kuliah P3 Bahasa di prodi PGSD FKIP UAD.Penentuan subjek penelitian didasarkan jumlah kelas pada mata kuliah P3 Bahasa dan Sastra Indonesia. Jumlah kelas sebanyak 7 kelas dengan ratarata 45 mahasiswa per kelas. Mata kuliah ini merupakan bagian dari rumpun bahasa Indonesia yang mengimplementasikan 
berbagai kemampuan Content Knowledge maupun Pedagogic Knowledge. Sumber data yang digunakan adalah aktivitas perkuliahan makul P3 Bahasa Indonesia di prodi PGSD FKIP UAD.Sedangkan, data penelitian ini adalah kata-kata, dokumentasi, dan tindakan dalam perkuliahan P3 Bahasa dan Sastra Indonesia mahasiswa PGSD FKIP UAD.

Pengumpulan data penelitian ini menggunakan teknikwawancara mendalam yang digunakan untuk menggali informasi tentang pelaksanaan pembelajaran serta integrasiaspekPCKpadamahasiswapenempuh makul P3 Bahasa dan Sastra Indonesia PGSD FKIP UAD.Wawancara mahasiswa dilakukan dengan cararandomsampling. Sampel diambil berdasarkan kebutuhan dalan pemilahan kelompok/kelas.Jumlah kelas yang mengikuti mata kuliah P3 Bahasa dan Sastra sebanyak 8 kelas dengan rata-rata 45 mahasiswa per kelas. Secara randomsamplingsampel diambil 4 mahasiswa untuk dilakukan wawancara. Selanjutnya, dilakukan diskusi terfokus dengan teman sejawat untuk menentukan verifikasi data yang diperoleh.Wawancara dengan pakar/teman sejawat ditujukan untuk mendapatkan masukan, gambaran, dan arahan tentang internalisasi aspek PCK dalam pembelajaran makul P3 Bahasa dan Sastra Indonesia.

Selanjutnya, observasidilakukan terhadap proses pembelajaran dan interaksi mahasiswa di PGSD FKIP UAD. Diharapkan dengan teknik pengumpulan data ini, didapatkan sebuah gambaran awal tentang tindakan dan aktivitas PCK dalam pembelajaran mata kuliah P3 Bahasa dan Sastra Indonesia. Sedangkan, dokumentasi digunakan untuk memperoleh penegasan tentang dokumendokumen proses pembimbingan meliputi tahap perencanaan, implementasi, dan evaluasi.Teknik pemeriksaan keabsahan data menggunakan triangulasi sumber dan teknik. Analisis data menggunakan teknik analisis interaktif dimulai dari pengumpulan data, reduksi data, verifikasi data, dan penarikan simpulan.

\section{Hasil dan Pembahasan}

Seorang guru yang ingin pembelajarannya berjalan secara efektif, harus memahami dan mampu mengintegrasikan pengetahuan konten ke dalam pengetahuan kurikulum, pembelajaran, karakteristik siswa, dan cara pembelajarannya tidak hanya sekedar mengetahui isi (content) yang akan diajarkan.

Pengetahuan-pengetahuan tersebut dapat menuntun guru untuk merangkai situasi pembelajaran pada kebutuhan individu dan kelompok siswa.Pengetahuan itulah yang dinamakan Pedagogical Content Knowledge (PCK). Menurut Anwar,dkk (2016) PCK merupakan kumpulan pengetahuan yang terintegrasi, konsep, kepercayaan dan nilai yang dikembangkan guru pada situasi mengajar.

Pedagogical Content Knowledge (PCK) ialah kombinasi dari dua unsur yaitu Content Knowledge dan Pedagogical Knowledge. Kedua unsur tersebut terkait dengan empat tuntutan kompetensi yang harus dimiliki guru dan dosen di Indonesia, dua diantaranya adalah kompetensi profesional dan pedagogik (Sulastri, 2016).Content Knowledge guru yang bagus tidak dapat terjadi jika Pedagogical Knowledge guru tidak bagus.Terkait dengan Pedagogical Content Knowledge (PCK) yang terdiri dari Content Knowledge dan Pedagogical Knowledge yang seharusnya dimiliki seorang guru, pemerintah Republik Indonesia pun sebenarnya telah mengatur hal tersebut melalui PP No. 74 tahun 2008. PCK dapat dikembangkan oleh guru dari waktu ke waktu melalui pengalaman tentang bagaimana cara mengajarkan konten tertentu dengan cara tertentu untuk meningkatkan pemahaman siswa. Menurut Resbiantoro (2016),Pedagogical Content Knowledge (PCK) dapat dipahami sebagai pengetahuan tentang materi dan cara mengajarkannya, yang meliputi aspek-aspek penunjang tugas guru untuk melaksanakan pembelajaran. $P C K$ merupakan pengenal bahwa mengajar bukan hanya sekedar transfer pengetahuan dan keterampilan, akan tetapi lebih kompleks dari itu karena mencakup aktivitas yang kompleks 
dan membutuhkan berbagai keputusan dan tanggapan akan kebutuhan belajar siswa (Dazrullisa,2017).

Calon guru dengan pengalaman mengajar di kelas yang masih kurang tak pelak akan mempengaruhi dalam pengetahuan Pedagogical Content Knowledge (PCK) yang dimiliki, dibandingkan dengan guru yang berpengalaman. Bagi calon guru yang akan dalam mengembangkan PCK dapat dilakukan pembekalan untuk menggali bagian-bagian dari PCK secara menyeluruh. Hal ini dilakukan karena pada dasarnya PCK merupakan hubungan dinamis antara bagian-bagian tersebut dan sangat berkaitan dengan segi praktik.Menurut Hartati (2016), Ada beberapa cara agar guru memiliki PCK, yakni: melakukan refleksi setelah mengajar; wawancara/dialog dengan murid; diskusi dengan guru lain; serta kegiatan yang mendukung, seperti seminar, PTK (Penelitian Tindakan Kelas), kursus, masuk organisasi profesi, serta menulis di jurnal dan media massa. PCK yang baik identik dengan guru yang profesional. Namun, guru yang profesional bukan dilahirkan, akan tetapi dibentuk melalui serangkaian proses dan waktu yang panjang.

Secara sederhana Pedagogical Content Knowledge $(P C K)$ dapat diartikan sebagai gambaran tentang bagaimana seorang guru mengajarkan suatu subjek dengan mengakses apa yang dia ketahui tentang subjek tersebut dan apa yang dia yakini sebagai cara mengajar yang baik pada konteks. seorang guru professional harus mempunyai dan mengetahui kemampuan PCK yang dimiliki. PCK yang baik mempunyai dampak terhadap ketercapaian konsep dan peningkatan kemampuan siswa.Kemampuan PCK guru terbentuk tidak hanya ketika sudah menjadi guru, tetapi juga dipengaruhi pada awal pembentukan yaitu masa pendidikan.Oleh karena itu, calon guru atau mahasiswa harus dibentuk untuk mempunyai PCK yang baik dimulai sejak awal pendidikan.

\section{Kajian Aspek Pedagogical Content Knowledge pada Mata Kuliah P3 Bahasa dan Sastra di Sd}

Salah satu topik kajian mengenai PCK yang menjadi fokus penelitian para peneliti adalah komponen-komponen atau unsur-unsur dari PCK. Shulman dalam (Sarkim,2015) mengidentifikasi unsur-unsur PCK yang meliputi: 1) topik-topik yang paling sering diajarkan; 2) cara-cara merepresentasikan pengetahuan yang paling tepat; 3) analogi; 4) contoh penjelasan; 5) cara-cara yang dapat membuat pembelajaran menjadi mudah; 6) prakonsepsi dan miskonsepsi para siswa. Unsur-unsur yang sudah disebutkan dapat membantu untuk menilai apakah seorang guru/ calon guru sudah memiliki PCK atau belum. Menurut Magnusson dalam Rubiantoro (2016) terdapat beberapa model PCK guru yang diusulkan yaitu dengan mengidentifikasi hubungan antara domain pengetahuan guru, meliputi: (1) pengetahuan materi pelajaran (subjectmatter), substansi maupun sintaknya, (2) pengetahuan pedagogi umum, dan (3) pengetahuan konteks materi, dan sumbersumber pengetahuan guru, (4) pengetahuan konten pedagogi (PCK).

Salah satu cara yang dapat dilakukan untuk mengetahui kemampuan calon guru adalah dengan menganalisis kemampuan mereka dalam menganalisis hasil kerja siswa sehingga dapat diketahui thinking knowledge siswa dalam menyelesaikan soal(Sulastri, 2016). Aspek penilaian PCK yang terdapat pada rubrik untuk menganalisis hasil kerja siswa menurut Koirala, et al (2007) yaitu 1) content knowledge and skill, 2) analysis of student work, dan 3) feedback to students. Pedagogical Content Knowledge (PCK) bisa dideskripsikan sebagai hubungan antara pengetahuan dasar dari konten dan pedagogi dengan ketiga bidang yang diperlukan dari konteks (Hurrel, 2013). Lebih jauh Hurrel (2013) menggambarkan ide Shulman tersebut sebagai berikut: 


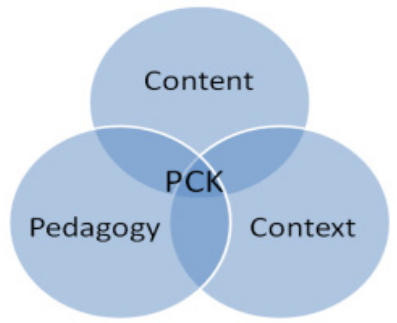

Gambar 1. Shulman dalam Hurrel (2013) domains of pedagogical content knowledge

\section{Implementasi Konsep Pedagogical Content Knowledge pada Mata Kuliah P3 Bahasa Dan Sastra di SD}

Mata kuliah pembelajaran dan praktik berbahasa indonesia (P3 Bahasa Indonesia) di Prodi PGSD FKIP UAD merupakan bagian dari makul rumpun bahasa Indonesia di Prodi PGSD. Implementasi konsep PCK dalam pembelajaran dapat dilakukan melalui beberapa kegiatan antara lain; pembelajaran, aktivitas, dan proyek penugasan lainnya. Berdasarkan hasil analisis data dijabarkan sebagai berikut.

a) Aspek pengetahuan konten kebahasaan

Proses pembelajaran yang dilakukan meliputi tatap muka dengan mengacu pada RPS yang telah dibuat. Capaian pembelajaran makul P3 Bahasa yaitu mahasiswa mampu memahami, mengembangkan, mengintegrasikan kemampuan ilmu kebahasaan dalam proses pembelajaran,mampu mengembangkan perangkat pembelajaran dan mempraktikkanya. Pada aspek pembelajaran, mahasiswa menyusun perangkat pembelajaran dengan mengacu pada $\mathrm{KI}$ dan $\mathrm{KD}$ yangtelah ditentukan. Selanjutnya, mahasiswa menggunakan kemampuan contentknowledge dengan memasukkan muatanmuatan ilmu kebahasaan dalam proses penyusunan perangkat pembelajaran.

Hasil analisis data menunjukkan kemampuan mahasiswa dalam mengintegrasikan contentknowledgeterlihat pada penyusunan bahan ajar modul. Modul yang dibuat telah memuat aspek PCK. Terlihat dalam penyusunan materi dan mengaitkan aspek kebahasaan seperti materi: suku kata,kosakata, kalimat, dan paragraf. Tataran integrasi PCK kebahasaan tidak hanya pada teks pendukung, tetapi juga latihan soal. Selain itu, penggunaaan intruksi kerja pada tugas yang dibuat sudah memenuhi aspek PCK. Aspek tersebut disajikan secara runtut baik eksplisit maupun implisit.

Aspek pengetahuan konten juga terlihat pada penyusunan rencana pembelajaran. Integrasi PCK terlihat pada penyusunan kegiatan pembelajaran pada RPP misalnya, siswa mampu mengomentari hasil kinerja teman. Hal ini menunjukkan bahwa aspek PCK materi berbicara. Kemampuan berbicara siswa ini dikaitkan dengan tagihan atau penilaian yang telah disusun yaitu penilaian sikap dan unjuk kerja, penilaian sikap dinilai dari aspek respon siswa terhadap kinerja teman lain, seperti saling menghargai, displin, dan tanggung jawab. Selanjutnya, unjuk kerja dinilai dari penampilan dengan mempertimbangkan aspek berbicara yang baik.

Terkait dengan tema-tema yang melingkupi pada pembelajaran SD, aspek konteks dijadikan sebuah bahan teks untuk mengaitkan pelajaran lain sesuai $\mathrm{KD}$ yang telah dibuat. Jadi, dalam aspek pengetahuan konten bahasa pembelajaran bersifat saling mengikat. Artinya, bahwa pembelajaran disesuaikan dengan konteks, konten, pedagodi sebagai penyampai untuk meraih indikator yang ditentukan. 
b) Analisis hasil kerja mahasiswa

Analisis hasil kerja digunakan sebagai tolak ukur keberhasilan pembelajaran. Dalam pembelajaran tematik, hasil unjuk kerja merupakan indikator keberhasilan proses pembelajaran. Misalnya, dalam subtema "Kegiatan Sehari-hari" hasil kerja siswa tidak hanya dalam konten dan konteks pembelajaran bahasa Indonesia, melainkan pembelajaran lain yang dibalut dalam tematik. Dapat juga satu analisis hasil kerja siswa dapat memuat lebih dari satu mata pelajaran. Sesungguhnya pembelajaran merupakan penggalian atau eksplorasi siswa dalam memadukan berbagai maca pengalaman belajar. Mulai dari bahasa, ilmu hitung, maupun ilmu lainnya yang bersifat universal (Sulastri, 2016).

Berdasarkan reduksi data, hasil kerja berupa bentuk soal dan kebervariasian jenis soal dapat dilihat dalam proyek yang telah dihasilkan. Berdasarkan hal tersebut, wujud PCK dapat diketahui dengan mengintegrasikan aspek kognitif, afektif, dan psikomotorik. Aspekaspek tersebut tertuang dalam soal yang dibuat di dalam modul, LKS, hand out, dll. Integrasi PCK dalam hasil kerja mahasiswa juga dapat ditemukan dalam pembuatan media pembelajaran inovatif. Media yang dihasilkan mengacu pada tema yang telah ditentukan dan tentunya bersifat umum. Hal ini dikarenakan, pembuatan media tidak dikhususkan pada mapel tertentu. Hasilnya dapat digunakan untuk media pembelajaran sesuai dengan subtema yang akan guru ajarkan.

Media pembelajaran yang dihasilkan dapat disajikan sesuai tema yang diharapkan. Beberapa kelemahan yang ditemukan dari analisis hasil kerja mahasiswa penempuh makul P3 Bahasa Indonesia yaitu, (1) belum sepenuhnyamengacupada spesifikasi pengguna, artinya media yang dibuat beberapa tidak merujuk pada subjek kelas awal dan kelas akhir; (2) media tematik yang dihasilkan masih seputar aspek kognitif, yaitu pengguna (siswa) masih dominan pada penguasaan kognitif; dan (3) media pembelajaran tematik yang dihasilkan masih berada dalam tataran sebagai penguat/pelengkap, artinya media bukan sebagai alat untuk memudahkan siswa dalam meraih indikator.

c) Umpan balik mahasiswa

Respon mahasiswa terhadap integrasi PCK dalam proses pembelajaran makul P3 bahasa bervariasi. Hasil wawancara yang dilakukan bahwa mahasiswa belum secara sadar bahwa integrasi PCK dalam pembelajaran dengan memasukan berbagai macam aspek antara lain aspek konten, konteks, maupun pedagogi. Berdasarkan hasil analisis menunjukkan umpan balik mahasiswa berupa kesulitan dalam mengintegrasikan secara eksplisit. Hal ini karena mahasiswa penempuh makul P3 Bahasa Indonesia belum memahami bagaimana mengaitkan antara KD, indikator, dan butir soal yang dikembangkan. Beberapa data ditemukan bahwa soal yang dibuat belum terkait dengan teks sebelumnya.

Umpan balik lainnya yaitu mahasiswa melakukan konfirmasi atas hasil yang dikerjakan. Hal ini dikarenakan pemahaman KD terhadap penentuan indikator masih dalam ranah kognitif. Dosen pengampu sebagai fasilitator memerikan pendampingan untuk 
menegaskan dan mengarahkan tentang penentuan indikator yang selanjutnya dikembangkan menjadi perangkat pembelajaran. Konten pedagogi dan konten pengetahuan disajikan dalam bentuk teks instruktif yang berguna untuk mengaktifkan ranah kognitif, afektif dan psikomotorik siswa. Sehingga, PCK yang dihasilkan melalui perangkat pembelajaran dapat tertuang secara menyeluruh.

\section{Simpulan}

Berdasarkan pembahasan di atas dapat disimpulkan bahwa PCK dalam makul P3 Bahasa Indonesia 1) kemampuan konten pengetahuan, 2) analisis hasil kerja, dan 3) umpan balik mahasiswa.Katiga konten tersebut dikembangkan melalui pengembangan perangkat pembelajaran meliputi RPP, modul, LKS, media, dan penilaian. Dengan dikembangkannya perangkat pembelajaran tersebut, maka PCK dalam sebuah materi pembelajaran untuk SD dapat dikemas dengan bentuk yang ideal sesuai dengan KD yang telah ditentukan

\section{Daftar Pustaka}

Agustiani, Riza. 2015.Profil Pengetahuan Pedagogik-Konten Mahasiswa Calon Guru Matematika Dalam Melaksanakan Pembelajaran Dengan Pendekatan PMRI.Bandung : Jurnal Pendidikan Matematika JPM RAFA. Vol. 1,No. 2:292.

Anwar,Yenny.dkk. 2016. Perkembangan Kemampuan Pedagogical Content Knowledge Calon Guru Biologi Pada Pendekatan Konkuren.Bandung : Jurnal Cakrawala Pendidikan. No. 349.

Christy, Kartika. 2015.Diskripsi Pedagogical Contein Knowledge Calon Guru SD pada Pembelajaran IPA. Prosiding SNPS. Surakarta: UNS.

Dapaepe, F., Marie, Evens., and Jan, Elen. 2015. Developing Pedagogical Content Knowledge: Lessons Learned from Intervention Studies. Hindawi Publishing Corporation.

Dazrullisa. 2017. Pedagogical Content Knowledge (PCK) Calon Guru Pada Materi Aljabar Siswa SMP. Aceh Barat: Jurnal MAJU. Vol. 4,No. $1: 2$.

Hartati, Tatat. 2016.PCK (Pedagogical Content Knowledge) bagi Mahasiswa S-2 Pendidikan Dasar dalam Rangka Implementasi Kurikulum 2013. Bandung :Jurnal Pendidikan Sains Sosial dan Kemanusiaan. Vol. 9,No. 1:174.

Hurrell, D. P. 2013. What Teachers Need to Know to Teach Mathematics: An Argument for a Reconceptualised Model.Australian Journal of Teacher Education. Vol. 38, 54-64.

Koirala, H.P., Davis, M., and Johnson, P. 2007 .Development of A Performance Assessment Task and Rubric to Measure Prospective Secondary School Mathematics Teachers' Pedagogical Content Knowledge and Skill. J Math Teacher Educ. 11:127-138.

Maryani, Ika. 2016. Strategi LPTK Dalam Pengembangan Kompetensi Pedagogik Calon Guru. Vol. 1,No. 2: 99-100.

Maryono. 2016.Profil pedagogical content knowledge (PCK) Mahasiswa Calon Guru Matematika Ditinjau Dari Kemampuan Akademiknya. Vol. 1,No. 1: 2-4.

Nengsih, Dewi Hernia. 2017. Analisis Kompetensi Pedagogik Guru Dalam Pengelolaan Proses Di Sd Negeri 10 Mandonga. Kendari :WAKAPENDIK Vol 2. No 7: 2. 
Purwianingsih, W. 2011.Pengembangan Program Pembekalan Pedagogical Content Knowledge (PCK) Bioteknologi Melalui Perkuliahan Kapita Selekta Biologi.Tesis. Universitas Pendidikan Indonesia, Bandung.http://repository.upi.edu/7 553/. Diakses tanggal 10 Desember 2017.

Resbiantoro, Gaguk. 2016. Analisis Pedagogical Content Knowledge (Pck) Terhadap Buku Guru Sd Kurikulum 2013. Tulungaggung : Schoralia. Vol.6, No 3 :153-156.

Sarkim, T. 2015.Pedagogical Content Knowlegde: Sebuah Konstruk untuk Memahami Kinerja Guru di Dalam Pembelajaran.Prosiding.Yogyakarta:ISSN :Semnas HFI XXIX.

Sulastri, Rini. 2016.Kajian Pedagogical Content Knowledge Calon Guru. Banda Aceh :Jurnal Pendidikan Serambi Ilmu. Vol. 24,No. 1:67-69.

Yulianti, Lia. 2017. Membangun Pedagogical Content Knowledge Calon Guru Fisika Melalui Praktek Pengalaman Lapangan Berbasis Lesson Study. Vol 1. No 1 : 17-18 